\title{
25 years or more after spinal cord injury: clinical conditions of individuals in the florence and stockholm areas
}

\author{
L Werhagen $^{1}$, S Aito ${ }^{2}$, L Tucci ${ }^{2}$, S Strayer ${ }^{3}$ and C Hultling ${ }^{4}$
}

Setting: Retrospective analysis and retrospective follow-up.

Introduction: Spinal cord injury (SCI) patients have today a nearly normal lifespan. Avoidance of medical complications is key to this end. The aim of the study was to analyse health in individuals surviving 25 years or more after traumatic SCl in Stockholm and Florence, and compare medical complications.

Methods: Data from the databases of the Spinal Unit of Florence and from the Spinalis, Stockholm were analysed. Patients included were C2-L 2, American Spinal Cord Association (ASIA) Impairment Scale (AIS) A-C, and $\geqslant 25$ years post traumatic SCl. Patients underwent a thorough neurological and general examination, and were interviewed about medical events during those years. Analysed data include: gender, age at injury, current age, neurological level, AIS, cause of injury, presence of neuropathic pain (NP), and spasticity and medical complications.

Results: A total of 66 Italian patients and 74 Swedish patients were included. The only statistical difference between the groups was cause of injury due to falls was higher in the Florence group $(P<0.01)$. Male/female ratio was $4: 1$. Traffic accidents were the most common cause of injury. In all, 60\% were paraplegics. Pressure ulcers (PU) occurred in nearly $60 \%$ and $32 \%$ experienced NP. Respiratory complications (RC) occurred in 25\% among tetraplegics. Neurological deterioration occurred in $14 \%$.

Conclusion: PU, bony fractures, spasticity and NP are important problems after SCI. RC are of clinical importance in the tetraplegics. Complications occur during all periods after injury. Many patients are otherwise healthy 25 years or more after SCl.

Spinal Cord (2012) 50, 243-246; doi:10.1038/sc.2011.130; published online 22 November 2011

Keywords: SCl; complications; spasticity; neuropathic pain; pressure ulcer

\section{INTRODUCTION}

Spinal cord injury (SCI) results in many medical complications, necessitating a complex, comprehensive and changing system of medical support. The annual incidence of traumatic SCI in Europe is about 17.5 patients per million. As in much of the world, $80 \%$ of patients are male, $40 \%$ of the patients are tetraplegic and $60 \%$ have a complete SCI. ${ }^{1,2}$

Acute care of SCI has changed during the years. Decompression of the neural elements, stabilisation of the spine and maintenance of tissue perfusion are fundamental in optimising outcome. In contrast to delayed surgery in past, most traumatic SCI patients today undergo surgery in the acute phase after injury. ${ }^{3}$ Timely urgent physical and rehabilitative care is essential not only for preserving neurological and spinal outcomes, but also for avoiding complications of hospitalisation and prolonged bed rest. ${ }^{4}$

Over time SCI takes its toll in many ways. Those surviving the acute injury will contend with further medical complications. Paralysis and compromised mobility initiates a cascade of problems resulting in cardiovascular deconditioning, muscle atrophy and weight gain. ${ }^{5}$ These leads to cardiovascular disease (CVD), altered glucose and lipid metabolism. Lack of mechanical stress leads to loss of bony mass leading to bone fragility and fractures. Lack of protective sensation results in pressure ulcers (PU). Release of reflex function results in spasticity and rigidity, which interfere with function.
Neuropathic pain (NP) frequently results from damage at peripheral and central elements of the nervous system.

Examination and contrast of various systems of SCI care can generate valuable insights in medical care. Close examination of practises has allowed SCI centres to adopt the most effective strategies, and move past ineffective ones. One example is the widespread adoption of guidelines for minimising occurrence of venous thromboembolic disease.

Though both the cities of strong Western European culture, Stockholm and Florence, are different with distinctive cultural influences, diet and medical systems. SCI care centres in Florence and Stockholm have been developed in the past three decades. Links between both centers allowed a systematic unified view of patients and histories, allowing grouping and contrasting of both the systems.

Our purpose in this study is to analyse characteristics of SCI patients in Stockholm and Florence. This may yield insight as to differences and similarities in care, as well as characterise current long-term survivors of SCI.

\section{MATERIALS AND METHODS}

Inclusion criteria were patients surviving with American Spinal Cord Association (ASIA) Impairment Scale (AIS) grades A-C at follow-up and duration of traumatic SCI 25 years or more. Both the centers use a database of patients to track injuries over the past three decades. These databases were used to generate

\footnotetext{
${ }^{1}$ Karolinska institutet Danderyds Sjukhus, Department of clinical sciences, Division of Rehabilitation Medicine, Danderyds hospital, Stockholm, Sweden; ${ }^{2}$ Spinal Unit Careggi, University Hospital, Florence, Italy; ${ }^{3}$ VA PaloAlto Health Care System, Palo Alto, CA, USA and ${ }^{4}$ Spinalis, Karolinska University Hospital, Stockholm, Sweden

Correspondence: Dr L Werhagen, Karolinska institutet Danderyds Sjukhus, Department of clinical sciences, Division of Rehabilitation Medicine, Danderyds hospital, Stockholm S-182 88, Sweden.

E-mail: lars.werhagen @ki.se

Received 18 April 2011; revised 6 October 2011; accepted 9 October 2011; published online 22 November 2011
} 
a list of patients that were recruited to the study. In Florence 86 patients that have survived at least 25 years after their injury were identified. We were not able to get in contact with 18 of them, in many cases because to inadequate address or telephone number, and two patients did not want to participate in the study. Finally, 66 Italian patients (IP) were included in the study. In Stockholm 80 patients were identified and 74 patients from Stockholm, designated Swedish patients (SP), were included and 6 patients did not agree to participate in the study. All patients in the Florence area with SCI receive their medical checkup at the Spinal Unit of Florence, and all SCI patients in Stockholm receive their controls at the Spinalis.

The cause of injury was categorized into the following groups: road traffic accidents, falling accidents, Sports accidents, diving accidents and other causes (such as gunshot, and so on).

The examinations of all patients in both the groups were performed by an experienced neurologist, one of the authors (LW). Patients underwent a thorough neurological and general examination. AIS grade was determined as per standard methodology defining both the level of injury and the degree of injury. ${ }^{6}$ Tetraplegic patients were defined as having a neurological level C4-C8 and paraplegic with thoracic or lumbar injury level.

The patients were interviewed by a structured questionnaire about medical complications, their family and occupational situations. When information was missing a telephone interview was performed.

Data analysed included gender, age at injury, current age, time since injury, occupational and family situation, neurological level, AIS, presence of spasticity and NP. Complications were noted, including presence or history of PU, bone fractures $(\mathrm{BF})$, respiratory complications (RC), neurological deterioration, depression, deep venous thrombosis, hypertension (HT), diabetes mellitus and CVD. RC included bronchopneumonia, atelectasis and respiratory insufficiency. When PU and BF were present, location and treatment (surgical or conservative) were studied.

The family situations were divided into: married, single and divorced/ widower. Occupational situations were divided into: (1) working full- or part-time, (2) not working/retired.

Working part-time was defined as working at least $25 \%$.

\section{Definitions}

PU: were graded in four grades 1-4 according to the National Pressure Ulcer Advisory Panel's updated pressure ulcer staging system where grade 1 was defined as none blanch able erythematic of intact skin, warmth, oedema, indurations and hardness, and the most sever grade 4 was defined as extensive destruction tissue, necrosis or damage of the muscle, bone, or supporting structures with or without full thickness skin loss. ${ }^{7}$

Spasticity: was defined as increased muscle tone (and an increase in the deep tendon reflexes). We used the Ashworth scale (0-4). ${ }^{8}$ Grade 1 was defined as a slight increase in muscle tone, manifested by a catch and release or minimal resistance at the end of the range of motion when the affected part(s) is moved in flexion or extension, and the most severe grade 4 was defined as affected part(s) rigid in flexion or extension.

Pain was classified as neuropathic when in an area with decreased sensibility and without evidence of non-neurological injury or inflammation. ${ }^{9} \mathrm{NP}$ is divided between at-level or below-level NP.

Diabetes mellitus was present when a fasting blood glucose was $>6.0 \mathrm{mmoll}^{-1}$, and/or when the patient was under glucose modifying medication.

HT was considered present when blood pressure was $>130 / 85$, and/or when the patient was under antihypertensive medication.

CVD included heart failure, myocardial infarction and angina pectoris.

Depression was considered present when the patients experienced depressed mood, loss of interest or pleasure, feelings of guilt or low self-worth, disturbed sleep or appetite, low energy, and poor concentration or under pharmacological or psychological treatment for depression.

\section{Analysis of data}

Groups and subgroups are presented as absolute numbers and percentages. Comparisons between groups were made by $\chi^{2}$-tests or by Fischer's exact test when the numbers were too small to allow $\chi^{2}$-test. $P<0.05$ were considered significant.

\section{Ethics}

The study was approved by the Ethics committee at Karolinska Institutet (2004/4:7) and (2006/594:31).

\section{RESULTS}

Sixty-six IP and 74 SP, in total 140 patients with a traumatic SCI of greater than 25 years duration were studied in the present analysis. In both the countries, $75 \%$ of patients were AIS A and $60 \%$ were paraplegic. Road traffic accidents followed by falls were the most common causes of injury.

In both the counties about half of the patients underwent surgery after their injury. For mean age at the time of injury, male/female ratio and time since injury, cause of injury, AIS, the neurological level and treatment of lesion see Table 1.

Spasticity was the most common complication followed by PU. In both the countries spasticity was more often present in patients with higher lesions.

PU occurred during all periods after injury. The most common location was sacral for both the groups followed by the ischium.

When NP was present, two-third of the patients in both countries experienced below-level NP.

The most common location of BF was the femur followed by tibia. BF occurred even after minor traumas.

The most common cause of neurological deterioration was syringomyelia followed by tethered cord.

RC occurred in $25 \%$ of the tetraplegics in both the countries.

Epilepsy was present in one IP and in none of the SP.

Only small differences were seen in long-term medical complication between IP and SP (Table 2).

For the presence and treatment of PU and BF see Table 3.

For family and occupational situation see Table 4 .

Table 1 Gender, age at the time of injury, actual age, time since injury, causes of lesion, treatment of lesion, AIS and neurological level in patients in Florence and Stockholm 25 years or more after traumatic spinal cord injury

\begin{tabular}{|c|c|c|}
\hline Variables & Italian patients & Swedish patients \\
\hline Male & $48(73 \%)$ & $58(78 \%)$ \\
\hline Female & $18(27 \%)$ & $16(22 \%)$ \\
\hline Age at the time of injury (years) & $23(4-53)$ & $21(0-45)$ \\
\hline Actual age (years) & $56(31-82)$ & $52(33-80)$ \\
\hline Time since injury (years) & $33(25-60)$ & $31(25-54)$ \\
\hline \multicolumn{3}{|l|}{ Cause of lesion } \\
\hline Falling accidents & $23(35 \%)^{a}$ & $11(15 \%)$ \\
\hline Road traffic accidents & $31(47 \%)$ & $44(59 \%)$ \\
\hline Sports accidents & $1(2 \%)$ & $5(7 \%)$ \\
\hline Diving accidents & $7(11 \%)$ & $9(12 \%)$ \\
\hline Other & $4(5 \%)$ & $5(7 \%)$ \\
\hline \multicolumn{3}{|l|}{ Treatment of lesion } \\
\hline Surgical & $36(55 \%)$ & $41(55 \%)$ \\
\hline Conservative & $30(45 \%)$ & $33(45 \%)$ \\
\hline Tetraplegi & $27(41 \%)$ & $25(34 \%)$ \\
\hline Paraplegi & $39(59 \%)$ & $49(66 \%)$ \\
\hline \multicolumn{3}{|l|}{ AIS } \\
\hline A & $49(74 \%)$ & $56(76 \%)$ \\
\hline B & $13(20 \%)$ & $10(14 \%)$ \\
\hline $\mathrm{C}$ & $4(6 \%)$ & $8(10 \%)$ \\
\hline
\end{tabular}

Abbreviation: AIS, American Spinal Cord Association (ASIA) Impairment Scale (AIS) grades $\mathrm{A}-\mathrm{C}$.

a Statistical significance $\chi^{2}=6.529$, degrees of freedom $(\mathrm{df})=1, P=0.0106$. 
Table 2 Long-term medical complications 25 years or more after traumatic spinal cord injury

\begin{tabular}{lcc}
\hline Medical complication & Italian patients (\%) & Swedish patients (\%) \\
\hline Spasticity & $43(65)$ & $45(61$ \\
Pressure ulcers & $38(59$ & $40(57)$ \\
Neuropathic pain & $21(32$ & $24(32$ \\
Bone fractures & $12(18)$ & $18(24)$ \\
Neurological deterioration & $9(14)$ & $10(14)$ \\
Diabetes mellitus & $7(10)$ & $5(6)$ \\
Cardiovascular disease & $6(9)$ & $4(5)$ \\
Hypertension & $7(10)$ & $4(5)$ \\
Deep venous thrombosis & $5(7)$ & $3(4)$ \\
Depression & $4(6)$ & $7(10)$ \\
\hline
\end{tabular}

Table 3 Pressure sores and bone fractures localisation and treatment during $\mathbf{2 5}$ years or more after spinal cord injury in patients in Florence and Stockholm area

\begin{tabular}{lcc}
\hline Pressure sores & Italian patients (\%) & Swedish patients (\%) \\
\hline Ischial & $11 / 38(29)$ & $12 / 40(30)$ \\
Sacral & $22 / 38(48)$ & $18 / 40(45)$ \\
Other & $5 / 38(13)$ & $10 / 40(25)$ \\
Treatment & & \\
$\quad$ Surgical & $17 / 38(45)$ & $13 / 40(32)$ \\
Conservative & $21 / 38(55)$ & $27 / 40(68)$ \\
& & \\
Bone fractures & & $9 / 18(50)$ \\
Femur & $6 / 12(50)$ & $2 / 18(11)$ \\
Tibial & $3 / 12(25)$ & $7 / 18(39)$ \\
Other & $3 / 12(25)$ & \\
Treatment & & $9 / 18(50)$ \\
Surgical & $6 / 12(50)$ & $9 / 18(50)$ \\
Conservative & $6 / 12(50)$ & \\
\hline
\end{tabular}

\section{DISCUSSION}

In our investigation, incidence of patient injury and outcome characteristics, medical complications and demographics were surprisingly similar. The only finding that showed statistical significance was some difference in cause of SCI.

Both Sweden and Italy are well-developed Western European countries. They have much in common, but there are differences in how people live and how health systems function. Spinal injury medical care has been well established in both the settings. Starting in 1978, the Spinal Unit of Florence has 32 years of experience of acute and long-term SCI care. Clinical activity at the Spinalis Outpatient Clinic in Stockholm commenced in 1992. Both the systems provide lifetime long-term care, outpatient SCI services and annual comprehensive evaluation, while primary every day care is provided by the local health system.

These findings are much in keeping with reports of medical complications in other world SCI treatment sites. ${ }^{10}$ Leading longterm medical complications are PU, NP, spasticity and respiratory compromise. ${ }^{11}$ Many patients are otherwise healthy 25 years or more after a traumatic SCI.
Table 4 Family and occupational situation in traumatic spinal cord injury patients 25 years or more after injury

\begin{tabular}{lcc}
\hline Variables & Italian patients (\%) & Swedish patients (\%) \\
\hline Married & $30(46)$ & $28(38)$ \\
Single & $32(48)$ & $38(51)$ \\
Divorced/widower & $4(6)$ & $8(11)$ \\
Occupational situation working & $26(39)$ & $28(38)$ \\
at least part-time & & \\
Not working retired & $40(61)$ & $46(62)$ \\
\hline
\end{tabular}

As found in other studies, the most common cause of traumatic SCI is road traffic accidents, followed by fall, whereas diving accidents are the most common sports injury. In Florence, falling accidents was more common than in Stockholm. This might be explained by the local practise of climbing trees to pick olives. As with other SCI studies, we found a strong male predominance (73\% SP and 78\% IP), and $60 \%$ of the patients were paraplegic. This is in contrast to some data showing increased numbers of tetraplegic patients relative to paraplegia. ${ }^{12}$ However, the patients included in our study had their SCI at least 25 years ago that might explain the difference.

$\mathrm{PU}$ was found to be the most common long-term complication. Nearly half of the patients with PU were treated surgically. Minor PU (grade 1-2) are difficult to count and not included in the present study. Many patients have minor ulcers recognised and self-treated conservatively and successfully. Several patients have had more than one PU. Finally, we noted that PU occur during all time periods after injury.

Neurological complications were common. Spasticity occurred in $60 \%$ of included patients in both the centres. However, we did not study the treatment and the impact on daily life. In the present, it was found that spasticity was more prevalent in higher lesions in both the countries. The prevalence of NP was $32 \%$ in both the countries. In a study done by Werhagen et al., ${ }^{13}$ the prevalence was $40 \%$, including patients with AIS D. Our study showed like the study done by Werhagen et al. ${ }^{13}$ that below-level NP was more common than atlevel NP. Neurological deterioration was found in $14 \%$ of the patients in both the countries. This figure is $<20 \%$, the estimation in the article by Nielsen et al. ${ }^{14}$ This may have to do with the fact that our duration of injury was somewhat less than in the Nielsen study. Nielsen et al. showed that syringomyelia can give rise to symptoms 26 years after injury.

Wahman et al. ${ }^{15,16}$ found that persons in Sweden with paraplegia report increased prevalence of HT and diabetes mellitus compared with the general population. However, in studies done by Soden et al. ${ }^{17}$ and Lindal et al., ${ }^{18}$ no increased CVD risk was found when comparing a disabled subgroup with a non-disabled cohort. In contrast, the prevalence of CVD, diabetes mellitus and HT is higher in the present study, both in Florence and Stockholm, compared with the ULF (Undersökning av Levnadsvanor) data. The data from the Swedish Annual Level-of-Living Survey ULF has been compiled since 1975 by and under the authority of the Swedish government. It represents a nationwide survey covering all persons in the age range 16-84 years, focusing on health issues and living conditions. Data were collected by interviews, the results of which were published in annual reports.

The ULF data used in the present study were collected between the years 2003 and 2005, and represent a subset of the total ULF dataset 
having persons of like age and gender distribution, and region of residence as that of the SCI group. ${ }^{19}$ This finding of increased CVD, diabetes and HT among individuals with SCI is much in keeping with findings seen by Bauman et al. ${ }^{20}$

Depression can often be difficult to detect by the examining team. Therefore, one can estimate that the true number of patients with depression is higher than we found in the present study.

In both Stockholm and Florence about one-third of patients were working. The mean age for patients not working was slightly higher than for those who were working, as some of the patients studied in both the countries had reached normal retirement age of 65 .

One strength of our investigation is the uniformity of medical evaluations by our clinicians between centres. Similarly, the medical clinics in each location provide comprehensive care to all requiring it, minimising patients lost to follow-up.

Our study can be criticised in several ways. The present study focused on patients that were AIS A-C, and did not include AIS D-E. Patients that are AIS A-C are wheelchair dependant and have major disability, whereas those who are AIS D are often walkers. Those recovering to AIS E are frequently lost to follow-up, having recovered enough not to need our services. Because to the fact that in Stockholm the database only include patients that are still alive, it was not possible to study how many patients with SCI that has died during the years. However, the patients that have died during the years and the causes of death deserve a separate study.

Medical complications were not studied in detail. Our purpose was to study the frequency of complications as well as which complications were most common. We did not investigate functional or psychological impact of complications, or the effect of medication. We did not address all complications that occur at a SCI per se. One reason for that is that it is difficult to determine the level of severity and the amount of frustration that complications or shortcomings generates. The scope of the study was more to get an all overview of complications that is present rather than examining quality of life for this specific cohort of patients, who survived 25 years with a SCI. Significantly, in studying complications after SCI we have not included bowel, bladder and sexual complications. These problems merit a separate investigation.

We were unable to compare other aspects of care: length of hospitalisation, surgeries, frequency of follow-up and medications used. Significantly this is a survivors study rather than a comprehensive survey of outcomes after SCI. It would be interesting to look at these variables among the patients that did not survive to 25 years.

\section{CONCLUSIONS}

Identification of long-term medical complications is important for the best outcome. The annual SCI examination may be best to identify imminent problems, avoid progression, and allow SCI survivors longevity and high life quality. Complications like BF and PU occurs during all periods after SCI. Comparisons of long-term complication in different countries have many uses, from assisting with planning to setting state health care budgets.

\section{DATA ARCHIVING}

There were no data to deposit.

\section{CONFLICT OF INTEREST}

The authors declare no conflict of interest.

1 Pagliacci MC, Celani MG, Zampolini M, Spizzichino L, Franceschini M, Baratta S et al. Gruppo Italiano Studio Epidemiologico Mielolesioni. An Italian survey of traumatic spinal cord injury. The Gruppo Italiano Studio Epidemiologico Mielolesioni Study. Arch Phys Med Rehabil 2003; 84: 1266-1275.

2 Biering-Sörensen F, Pedersen V, Clausen S. Epidemiology of spinal cord lesions in Denmark. Paraplegia 1990; 28: 105-118.

3 Wuermser LA, Ho CH, Chiodo AE, Priebe MM, Kirshblum SC, Scelza WM. Spinal cord injury medicine. 2. Acute care management of traumatic and non-traumatic injury. Arch 2007; 88 (Suppl 1): S55-S61.

4 Kirshblum SC, Priebe MM, Ho CH, Scelza WM, Chiodo AE, Wuermser LA. Spinal cord injury medicine. 3. Rehabilitation phase after acute spinal cord injury. Arch Phys Med Rehabil 2007; 88 (Suppl 1): S62-S70.

5 McKinley WO, Gittler MS, Kirshblum SC, Stiens SA, Groah SL. Spinal cord injury medicine. 2. Medical complications after spinal cord injury: identification and management. Arch Phys Med Rehabil 2002; 83 (Suppl 1): S58-S64, S90-S98.

6 Ditunno JF, Donovan WH, Maynard FM. ASIAS. In: Ditunno JFDWHM, FM (eds). Reference Manual for the International Standards for Neurological and Functional Classification of Spinal Cord Injury. ASIA: Chicago, 1994.

7 Black J, Baharestani MM, Cuddigan J, Dorner B, Edsberg L, Langemo D et al. National Pressure Ulcer Advisory Panel National Pressure Ulcer Advisory Panel's updated pressure ulcer staging system. Adv Skin Wound Care 2007; 20: 269-274.

8 Lee KC, Carson L, Kannin E, Patterson V. The Ashworth scale: a reliable and reproducible method of measuring spasticity. J Neuro Rehab 1989; 3: 205-209.

9 Siddall JP, Yezierski RP, Loeser JD. Pain Following Spinal Cord Injury: Clinical Features, Prevalence, and Taxonomy, Technical corner from IASP Newsletter 2000, p 3-78.

10 Chiodo AE, Scelza WM, Kirshblum SC, Wuermser LA, Ho CH, Priebe MM. Spinal Cord Injury Medicine. 5. Long-Term Medical Issues and Health Maintenance. Arch Phys Med Rehabil 2007; 88 (Suppl 1): S76-S83.

11 McKinley WO, Jackson AB, Cardenas DD, DeVivo MJ. Long-term medical complications after traumatic spinal cord injury: a regional model systems analysis. Arch Phys Med Rehabil 1999; 80: 1402-1410.

12 National Spinal Cord Injury Statistical Center. National spinal cord injury Fact Sheet 2010. National Spinal Cord Injury Statistical Center: Birmingham, Alabama, 2010.

13 Werhagen L Budh CN, Hultling C, Molander C. Neuropathic pain after traumatic spinal cord injury - relations to gender, spinal level, completeness, and age at the time of injury. Spinal Cord 2004; 42: 665-673.

14 Nielsen OA, Biering-Sorensen F, Bötel U, Gardner BP, Little J, Ohta H et al. Posttraumatic syringomyelia. Spinal Cord 1999; 37: 680-684.

15 Wahman K, Nash MS, Westgren N, Lewis JE, Seiger A, Levi R. Disease risk factors in persons with paraplegia: the Stockholm Spinal Cord Injury Study. J Rehabil.Med 2010; 42: 272-278.

16 Wahman K, Nash MS, Lewis JE, Seiger A, Levi R. Increased cardiovascular disease risk in Swedish persons with paraplegia: the Stockholm spinal Cord Injury Study. J Rehabil Med 2010; 42: 489-492.

17 Soden RJ, Walsh J, Middleton JW, Craven ML, Rutkowski SB, Yeo JD. Causes of death after spinal cord injury. Spinal Cord 2000; 38: 604-610.

18 Lindal IB, Snekkevik H, Aamodt G, Hjeltnes N, Stanghelle JK, Biering-Sorensen F. Mortality after spinal cord injury in Norway. J Rehabil Med 2007; 39: 145-151.

19 The Swedish Annual Level-of-living Survey. Survey of Living Condition 2003-2005. Swedish Statistics available from www.scb.se/pages/list.

20 Bauman WA, Spungen AM, Raza M, Rothstein J, Zhang RL, Zhong YG et al. Coronary artery disease: metabolic risk factors and latent disease in individuals with paraplegia. Mt Sinai J Med 1992; 59: 163-168. 